GESTÃO DA INFORMAÇÃO 


\section{TRANSFERÊNCIA DE CONHECIMENTO TECNOLÓGICO: ANÁLISE DOS FATORES INDUTORES E RESTRITIVOS À AQUISIÇÃO DE CONHECIMENTO EM DOIS HOSPITAIS DO NORTE DE ANGOLA}

TECHNOLOGICAL KNOWLEDGE TRANSFER: ANALYSIS OF THE INDUCTIVE AND RESTRICTING FACTORS OF KNOWLEDGE ACQUISITION

IN TWO HOSPITALS IN THE NORTH OF ANGOLA

José Márcio de Castro

Pontifícia Universidade Católica de Minas Gerais

Manuel Adelino Nascimento

Pontifícia Universidade Católica de Minas Gerais

Rodrigo Baroni Carvalho

Pontifícia Universidade Católica de Minas Gerais
Data de submissão: 10 ago. 20 |7. Data de aprovação: 20 jan. 20 ।8. Sistema de avaliação: Double blind review. Universidade FUMEC / FACE. Prof. Dr. Henrique Cordeiro Martins. Prof. Dr. Cid Gonçalves Filho.

RESUMO

O artigo se propõe a investigar a dinâmica da transferência de conhecimento entre fornecedores de equipamentos médico-hospitalares para os hospitais. Partindo-se de uma perspectiva teórica sobre a transferência de conhecimento, discutiram-se os diversos fatores que podem induzir ou dificultar tal processo. A pesquisa de natureza qualitativa abrangeu dois estudos de casos de hospitais de referência da região Norte de Angola, que possuem equipamentos tecnológicos adquiridos de fornecedores estrangeiros. Os resultados apontam que os fatores como qualidade do relacionamento entre fonte e receptora e proximidade cultural exercem influência importante na transferência de conhecimento entre as empresas fornecedoras e os hospitais. A capacidade para transferir o conhecimento e a motivação da fonte, a capacidade absortiva e motivação da receptora emergem também como fatores relevantes para a transferência de conhecimento.

PALAVRAS-CHAVE

Transferência de conhecimento. Capacidade absortiva. Gestão do conhecimento. 


\section{ABSTRACT}

The research objective is to investigate the knowledge transfer dynamics from equipment suppliers to hospitals. From a theoretical perspective of knowledge transfer, the inductive and restricting factors of this process were discussed. The qualitative research comprised two case studies of reference hospitals in the north of Angola that have acquired technological equipment from foreign suppliers. The results have shown that factors such as relationship quality and cultural proximity between the knowledge source and the receiver played an important role on knowledge transfer from suppliers to hospitals. The transferring ability and the source motivation and also the absorptive capacity and receiver motivation have relevant influence on knowledge transfer.

\section{KEYWORDS}

Knowledge transfer. Absorptive capacity. Knowledge management.

\section{INTRODUÇÃO}

Para atender melhor as necessidades dos seus clientes ou mesmo conseguir vantagens em relação aos seus concorrentes, a criação e ou aquisição de conhecimentos externos tornou-se estratégica e decisiva para o desenvolvimento interno de capacidades organizacionais (VINDING, 2000; LIAO; FEI; CHEN, 2007; WIJK; JANSEN; LYLES, 2008; AHMED; JIMÉNEZ-JIMÉNEZ; MARTÍNEZ-COSTA, 20I3). Nesse contexto, a transferência de conhecimento assume um papel decisivo para as organizações que precisam inovar (EASTERBY-SMITH; LYLES; PETERAF, 2009), mas que tem limitações no desenvolvimento de atividades de P\&D. A transferência de conhecimento é caracterizada como um processo de aprendizagem na qual uma organização é afetada pela experiência de outra (ARGOTE; INGRAM, 2000; WIJK; JANSEN; LYLES, 2008). Entretanto, a transferência de conhecimento é um dos arranjos mais dificeis, visto que transferir conhecimento tem se mostrado uma atividade complexa e demorada (SZULANSKI, 1996; PÉREZNORDTVERDT et al., 2008; CAMPOS; FERREIRA; SILVA, 2008) e no qual diversos fatores podem concorrer para estimular ou dificultar o compartilhamento entre fonte e receptor.

Em Angola, a reabilitação, a construção e a modernização de hospitais têm sido motivo de preocupação em razão da grande quantidade de equipamentos que vêm sendo instalados nos hospitais provinciais por diversas firmas estrangeiras, demandando a transferência de conhecimentos tecnológicos. Nesses termos, o objetivo geral dessa pesquisa é investigar a dinâmica da transferência de conhecimento de fornecedores de equipamentos para hospitais, considerando os fatores indutores e dificuldades do processo.

Para além da introdução, o artigo está organizado da seguinte forma: 0 item 2 con- 
templa o referencial teórico com ênfase na transferência do conhecimento interfirmas e seus antecedentes; o item 3 contém o detalhamento da metodologia de pesquisa; o item 4 compreende a análise comparativa dos casos dos hospitais angolanos, aprofundando os aspectos da qualidade do relacionamento, proximidade cultural, capacidade para transferir e motivação da fonte, capacidade absortiva e motivação da receptora; o item 5 compreende as considerações finais e as discussões sobre as limitações e trabalhos futuros.

\section{REFERENCIAL TEÓRICO Transferência de conhecimento interfirmas}

O conhecimento, atualmente, é tido como o bem mais valioso e o motor das organizações, principalmente, em razão da criação contínua de novos conhecimentos tecnológicos, fundamentais para o crescimento e sustentabilidade competitiva (NONAKA; TAKEUCHI, 1997; PÉREZ-NORDTVEDT et al., 2008; EASTERBY-SMITH et al., 2009; LI; HSIEH, 2009). Tais conhecimentos podem ser geralmente tipificados em conhecimentos tácitos e explícitos. $\mathrm{O}$ conhecimento tácito é caracterizado como pessoal e específico ao contexto em que foi criado e, em razão disso, é difícil de ser formulado e comunicado (NONAKA; TAKEUCHI, 1997). Por essa razão, a sua transferência requer uma estreita interação e considerável entendimento comum e confiança entre os atores (JASIMUDDIN, 2007), por ser pessoal e dependente do contexto e não do corpo de fatos ou conjunto de instruções que alguém detém ou pode explicar a outros (LAM, 2000; EASTERBY-SMITH; LYLES;TSANG, 2008).

Por seu turno, o conhecimento explícito refere-se àquele conhecimento que pode ser transmitido em linguagem formal e sistemática, ou seja, aquele que pode ser traduzido por palavras e códigos, sistemas, protótipos, entre outros (NONAKA; TAKEUCHI, 1997; LUBIT, 200 I; JASIMUDDIN, 2007), ou seja, expressado de maneira precisa, concentrado e transferido ao longo do tempo e do espaço, independentemente dos assuntos a que se refere.

Tanto os conhecimentos tácitos como os explícitos contribuem para que a organização desenvolva capacidades e habilidades internas, bem como conhecimentos que são difíceis de serem imitados (NONAKA; TAKEUCHI, 1997; LUBIT, 200I; LAM, 2000; LI; HSIEH, 2009). A gestão do conhecimento comporta cinco fases designadas como geração, transferência, acumulação, adoção e difusão de conhecimento na organização (DISTERER, 200 I). Uma vez que o conhecimento é um recurso crítico e estratégico para as organizações (BRESMAN et al., 2010), um dos processos cruciais na gestão do conhecimento é a transferência, visto que muitas organizações podem ter barreiras para a sua criação, como por exemplo, os custos e incertezas das atividades internas de P\&D (Pesquisa e Desenvolvimento) (WIJK et al., 2008; EASTERBY-SMITH et al., 2009).

A transferência de conhecimento é definida como um processo pelo qual os atores organizacionais (equipes, unidades ou organizações) trocam, recebem conhecimentos e são influenciados pela experiência e conhecimento dos outros (ARGOTE; INGRAM, 2000; WIJK et al., 2008; KUMAR; GANESH, 2009). A transferência é considerada um fenômeno complexo e os resultados, em muitos casos, têm sido considerados pífios (EASTERBY-SMITH; 
LYLES; TSANG, 2008). A transferência de conhecimento organizacional, também, pode ser vista sob dois ângulos distintos e complementares, denominados de transferência intra e interorganizacional (EASTERBY-SMITH et al.,2008). A transferência de conhecimento interorganizacional (foco dessa pesquisa) ocorre entre duas ou mais organizações distintas e tem se revelado mais difícil (EASTERBY-SMITH et al., 2008) e complexa que a transferência de conhecimentos intraorganizacional, que se processa de forma funcional ou entre unidades de uma organização.

Alguns fatores têm sido reconhecidos na literatura como barreiras comuns ao processo de transferência, tais como: i) ausência de definição clara das condições nas quais o conhecimento será adquirido e utilizado; ii) ausência de experiências relacionadas com o conhecimento adquirido; iii) resistência do destinatário em receber o conhecimento de fora; iv) falta de motivação em compartilhar o conhecimento; e, v) deficiente capacidade de absorção e problemas de comunicação entre a fonte e o destinatário, entre outros (SZULANSKI, 1996; EASTERBY-SMITH et al., 2008).

De forma geral, no processo de transferência de conhecimento, quatro conjuntos de fatores concorrem para o êxito do processo, sobretudo, os recursos e as capacidades, tanto da fonte, quanto do receptor, a natureza do conhecimento que está sendo transferido e a dinâmica do relacionamento entre a fonte e a receptora (EASTERBY-SMITH et al., 2008;ALCARÁ et al., 2009). Na dinâmica do relacionamento entre as partes, os principais fatores relacionados com o processo de transferência discutido na literatura são: a qualidade do relacionamento e proximidade cultural. Especificamente relacionados com o receptor podem-se destacar a capacidade de absorção e a motivação. Quanto aos fatores relacionados à fonte, podem-se destacar a capacidade para transferir e a motivação para ensinar. Cada um desses fatores e as consequências para a transferência de conhecimento serão discutidos a seguir.

\section{Fatores antecedentes da transferência de conhecimento}

A qualidade de relacionamento se refere ao grau em que as relações entre a fonte e o destinatário do conhecimento são estreitas e baseadas na confiança (PÉREZNORDTVEDT et al., 2008; CASTRO; GUIMARÃES; DINIZ, 20I3a).A consequência é que um relacionamento de qualidade entre a fonte e o destinatário contribui para interações mais significativas entre as partes, resultando em uma transferência de conhecimento caracterizada por menores custos no processo (PÉREZ- NORDTVEDT et al., 2008; CASTRO; DINIZ; DUARTE; DRESSLER; CARVALHO, 20I3b).

Ao discutir a qualidade do relacionamento entre fonte e receptora, emergem alguns atributos que permitem caracterizar melhor esse construto, tais como intensidade de vínculos, proximidade físico-geográfica e confiança (ARGOTE; INGRAM, 2000; PÉREZ-NORDTVEDT et al., 2008; EASTERBY-SMITH et al., 2008;WIJK et al., 2008; CASTRO et al., 20।3b). A intensidade de vínculo entre organizações se manifesta por meio da interação desenvolvida mediante comunicações, visitas e reuniões frequentes, por meio dos quais a transferência acontece (BRESMAN et al., 20I0), enquanto a proximidade ou distância geográfica são relevantes, também, para $\circ$ entendimento da qualidade de re- 
lacionamento entre os diferentes atores (CASTRO et al., 20I3b). No contexto da transferência de conhecimentos, a proximidade (ou a distância) cultural é considerada, também, como um fator importante, haja vista que valores e crenças similares entre a fonte e o receptor são benéficos para transferir e compartilhar conhecimentos (BRESMAN et al., 2010; PÉREZNORDTVEDT et al., 2008).

A proximidade cultural entre organizações contribui para a facilidade da comunicação entre os membros e tornar suas ações mais legítimas e compreensíveis (ARGOTE; INGRAM, 2000; EASTERBY-SMITH et al., 2008; CHIRICO; SALVATO, 20I4). Contrariamente, a distância cultural pode produzir efeitos negativos para o processo de transferência de conhecimento, tais como a redução da conexão social entre as organizações e a diminuição da capacidade absortiva da receptora, em razão, principalmente, da influência que as pessoas vão sofrer na forma de interpretar e fazer uso do conhecimento (BJORKMAN; STAHL; VAARA, 2007; EASTERBY-SMITH et al., 2008; CASTRO et al., 20I3b). Portanto, a existência de uma linguagem que ambas as partes compreendam pode diminuir as incertezas durante o processo de transferência de conhecimento e, portanto, contribuir para o estabelecimento de uma comunicação adequada entre a fonte e o destinatário (SZULANSKI, 1996; DISTERER, 2003; CASTRO et al., 20I3a).

No âmbito da receptora, dois fatores são especialmente importantes: a capacidade de absorção e a motivação para aprender.A capacidade absortiva do receptor diz respeito à capacidade de reconhecer o valor dos novos conhecimentos, bem como absorver, explorar e utilizar o referido co- nhecimento (COHEN; LEVINTHAL, 1990; VINDING, 2000; EASTERBY-SMITH et al., 2008). Vários estudos descrevem a capacidade de absorção a partir do resgate do conceito de Cohen e Levinthal (I 989: 569570) no qual a capacidade de absorção é concebida como "[...] a capacidade da empresa em identificar, assimilar e explorar o conhecimento do ambiente [...]" (ver, por exemplo, ZAHRA; GEORGE, 2002; EASTERBY-SMITH et al., 2008).

A capacidade absortiva pode ser vista sob dois âmbitos, ou seja, em relação ao indivíduo e à empresa. Em relação à capacidade individual, refere-se ao uso direto ou indireto do conhecimento adquirido pelo indivíduo. Por outro lado, a capacidade de absorção da empresa é definida como o conjunto de recursos de que a mesma possui, ou melhor, o conjunto das capacidades de absorção de seus funcionários (COHEN; LEVINTHAL, 1990;WIJK et al., 2008).

O segundo fator, a motivação da receptora, é considerada, atualmente, como um dos grandes desafios para as organizações, por contribuir para a transferência de conhecimento (SZULANSKI, 1996; PÉREZ-NORDTVEDT et al., 2008; CASTRO et al., 20l3b). A motivação é descrita por Pérez-Nordtvedt et al. (2008) como a intenção da organização destinatária em aprender novos conhecimentos, o que pode influenciar no fluxo de conhecimento entre as organizações.

Em relação à fonte, dois fatores são, também, relevantes: a capacidade de transferir e a motivação para ensinar. A capacidade para transferir é considerada como relevante para a transferência de conhecimento, pois influencia de maneira direta o processo entre a fonte e a receptora 
(ZANDER; KOGUT, 1995). Tal capacidade envolve, em algum nível, três recursos básicos que sustentam o conhecimento organizacional, nomeadamente, recursos humanos, materiais e técnicos (KUMAR; GANESH, 2009).

Todavia, embora os recursos acima mencionados sejam relevantes, a capacidade para transferir depende significativamente dos mecanismos utilizados no processo de transferência. Os mecanismos são os canais ou ferramentas utilizadas durante o processo de transferência de conhecimento entre indivíduos e organizações (BJORKMAN; GUNTER; VAARA, 2007; AUDRESTSCH; LEHMANN; WRIGHT, 20I4; BOZEMAN; RIMES; YOUTIE, 20I5). Dependendo do uso, podem ser tipificados em mecanismos de personalização e de codificação, que são relacionados, respectivamente, aos conhecimentos tácitos ou explícitos a serem transferidos (BRESMAN et al., 20I0).

Por outro lado, transferir conhecimentos requer que a fonte esteja, também, motivada a ensinar o conhecimento a outro (CASTRO et al., 20l3b). Em determinados momentos, a fonte ou a detentora do conhecimento pode estar insegura em compartilhar seu conhecimento por medo de perder a propriedade ou privilégio do saber (SZULANSKI, 1996). Outros aspectos que podem afetar a motivação são o fato da fonte não ser devidamente recompensada ou, ainda, a falta de disposição em dedicar tempo e recursos na transferência de conhecimento (SZULANSKI, 1996; CASTRO et al., 20।3b).

\section{METODOLOGIA DE PESQUISA}

Esta pesquisa tem como objetivo compreender os fatores indutores e restritivos à transferência de conhecimento a partir de aquisição de tecnologia. Com esse objetivo, optou-se por um estudo de casos comparativo de natureza qualitativa (EISENHARDT, 1989; YIN, 2005). A escolha do estudo qualitativo é adequada, principalmente, quando estudamos temas recentes ou que ainda carecem de esforços mais aprofundados de pesquisa (EISENHARDT, 1989) ou, ainda, quando as variáveis são complexas e imbricadas (YIN, 2005).

Para esta pesquisa, optou-se pelo estudo de dois casos no setor da saúde. Para tal, foram selecionados como unidades empíricas, dois hospitais da região centro norte de Angola, situadas nas províncias de Kwanza Norte e Malanje. Para este estudo, a seleção dos casos foi feita com base nos seguintes critérios: i) os hospitais escolhidos são unidades de referência no atendimento à assistência de saúde na região; ii) estão equipados com tecnologia provenientes de diferentes origens e fontes de abastecimento estrangeiras; iii) são hospitais que fazem aquisição de equipamento tecnológico; e, iv) há evidências que mostram dificuldades na transferência do conhecimento tecnológico dos equipamentos adquiridos e instalados.

A utilização de casos múltiplos permite aumentar a paossibilidade de estender os achados para outros ambeintes além dos casos estudados (TSANG, 20l4), o que contribui para se estabelecer o domínio no qual as descobertas de um estudo podem ser generalizadas teoricamente (Yin, 2005). Por fim, o uso de casos múltiplos também permite maior confiança nas novas descobertas por meio da lógica de replicação, e suas evidências são consideradas mais convincentes (MEYER, 200 I; YIN, 2005).

Para este estudo, foram usadas entrevistas em profundidade, observação dire- 
ta e indireta, documentos e arquivos, bem como notas de campo como instrumentos de coleta de dados. $O$ roteiro de entrevistas foi elaborado a partir da literatura sobre os principais fatores que afetam a transferência de conhecimentos. As entrevistas foram efetuadas com os gestores dos hospitais selecionados, responsáveis pela compra dos equipamentos, com os chefes de seções e os técnicos por serem os operadores diretos e responsáveis pela manutenção dos equipamentos. Para o primeiro caso, foram realizadas 15 (quinze) entrevistas em profundidade, sendo três feitas com os membros de direção do hospital, seis com os chefes de seções e as demais seis com os técnicos das diferentes seções (Quadro I). O tempo médio de cada entrevista foi de 45 minutos, gerando mais de trinta páginas de transcrição. Os respon- dentes foram selecionados de acordo com sua relevância na estrutura organizacional e criticidade (MEYER, 200 I), isto é, com indivíduos efetivamente relacionados com a utilização, gestão dos equipamentos e com o processo de transferência, detentores, portanto, de informações críticas para a compreensão do fenômeno e das variáveis que 0 afetam. No segundo caso, Hospital de Malanje, foram realizadas 16 (dezesseis) entrevistas, sendo três com membros de direção do hospital, seis como os chefes de seção e sete com os funcionários das diferentes áreas do hospital (Quadro I). 0 tempo médio de cada entrevista foi de 45 minutos, tendo gerado aproximadamente quarenta páginas de transcrição. Os critérios de seleção de entrevistados foram os mesmos utilizados no primeiro caso (MEYER, 200I).

\section{QUADRO 1 - Relação de entrevistados do Hospital do Kwanza Norte e do Hospital do Malanje}

\begin{tabular}{|c|c|c|c|}
\hline \multicolumn{2}{|r|}{ Hospital de Kwanza Norte } & \multicolumn{2}{|r|}{ Hospital de Malanje } \\
\hline Entrevista & Cargo & Entrevista & Cargo \\
\hline Entrevista 1 & Chefe do bloco operatório & Entrevista 1 & Técnico do bloco operatório \\
\hline Entrevista 2 & Técnico de Imagiologia & Entrevista 2 & Técnico do bloco operatório \\
\hline Entrevista 3 & Chefe do laboratório & Entrevista 3 & Técnico de hemoterapia \\
\hline Entrevista 4 & Técnico de estomatologia & Entrevista 4 & Chefe de hemoterapia \\
\hline Entrevista 5 & Chefe de hemoterapia & Entrevista 5 & Chefe do bloco operatório \\
\hline Entrevista 6 & Técnico do bloco operatório & Entrevista 6 & Diretora de enfermagem \\
\hline Entrevista 7 & Técnico do bloco operatório & Entrevista 7 & Supervisor do hospital \\
\hline Entrevista 8 & Técnica de diagnóstico & Entrevista 8 & Diretor clínico \\
\hline Entrevista 9 & Responsável da formação permanente & Entrevista 9 & Responsável da formação permanente \\
\hline Entrevista 10 & Supervisor do hospital & Entrevista 10 & Chefe do laboratório \\
\hline Entrevista 11 & Chefe da maternidade & Entrevista 11 & Técnico de diagnóstico \\
\hline Entrevista 12 & Técnica de diagnóstico & Entrevista 12 & Técnico de imagiologia (TAC) \\
\hline Entrevista 13 & Diretor clínico & Entrevista 13 & Diretor administrativo \\
\hline Entrevista 14 & Diretor de enfermagem & Entrevista 14 & Chefe de estomatologia \\
\hline Entrevista 15 & Diretor administrativo & Entrevista 15 & Técnico de hemoterapia \\
\hline & & Entrevista 16 & Técnico de imagiologia (RX) \\
\hline
\end{tabular}

Fonte: Dados da pesquisa 
Para além das entrevistas em profundidade, outra fonte de evidências utilizada foi o apontamento de notas de campo realizado no momento em que se entrou em contato direto com o ambiente da pesquisa. Foram também consultados documentos, como regulamentos internos, organogramas, notícias de jornais, Diário da República de Angola, inventários, relatório de treinamentos realizados e planos de atividades. Neste estudo, foi utilizada a análise de conteúdo para auxiliar o tratamento e a interpretação dos dados que foram coletados com base nas categorias de análises criadas (BARDIN, 20I I) como ilustrado no Quadro 2. Num primeiro momento, foi feito o relatório de cada caso (análise intracaso) e, posteriormente, a análise comparativa (análise intercasos) (ElSENHARDT, 1989).

\section{DESCRIÇÃO E ANÁLISE COMPARATIVA DOS CASOS Descrição dos casos}

O Hospital Geral do Kwanza Norte é a principal unidade hospitalar da província de mesmo nome situada no norte de Angola, abrigando vários serviços que permitem $\circ$ atendimento dos pacientes. Foi constituído em 1950, quando o governo português percebeu a necessidade de prestar assistência médica e medicamentosa à minoria da população branca residente na então cidade de Salazar, atual cidade de N'dalatando, capital da província. O Hospital Geral do Kwanza Norte conta com vários equipamentos distribuídos em várias seções, destacando-se como principais áreas que contribuem de forma direta para funcionamento do hospital, o laboratório, a imagiologia, o bloco operatório, hemoterapia e estomatologia. O hospital conta

QUADRO 2 - Categorias de análise utilizadas na pesquisa

\begin{tabular}{|c|c|c|}
\hline Dimensões & Categorias & Subcategorias \\
\hline \multirow{2}{*}{$\begin{array}{l}\text { Contexto Inter } \\
\text { organizacional }\end{array}$} & $\begin{array}{l}\text { Qualidade do } \\
\text { relacionamento }\end{array}$ & $\begin{array}{l}\text { - Intensidade de vínculo } \\
\text { - Proximidade física / geográfica } \\
\text { - Confiança }\end{array}$ \\
\hline & Proximidade cultural & $\begin{array}{l}\text { - Significados comuns e sistemas de valores similares } \\
\text { - Linguagem comum entre as partes }\end{array}$ \\
\hline \multirow[t]{2}{*}{ Receptora } & Capacidade absortiva & $\begin{array}{l}\text { - Capacidade da receptora de descobrir uma informação externa útil } \\
\text { - Nível de conhecimento prévio da receptora em relação ao assunto } \\
\text { - Capacidade da receptora de utilizar e compartilhar o conhecimento adquirido } \\
\text { - Grau de qualificação dos funcionários da firma receptora }\end{array}$ \\
\hline & $\begin{array}{l}\text { Motivação da } \\
\text { receptora }\end{array}$ & $\begin{array}{l}\text { - Disponibilidade para utilizar o conhecimento externo } \\
\text { - Atratividade da fonte }\end{array}$ \\
\hline \multirow[t]{2}{*}{ Fonte } & $\begin{array}{l}\text { Capacidade para } \\
\text { transferir }\end{array}$ & $\begin{array}{l}\text { - Alta expertise no conhecimento a ser transferido } \\
\text { - A fonte possui resultados superiores historicamente } \\
\text { - Credibilidade e importância estratégica } \\
\text { - Existência de parcerias anteriores interfirmas }\end{array}$ \\
\hline & Motivação da fonte & $\begin{array}{l}\text { - Disponibilidade para colaborar e transferir conhecimento crítico } \\
\text { - Sistema de incentivo e recompensa }\end{array}$ \\
\hline
\end{tabular}

Fonte: Elaborado pelos autores 
com um quadro de pessoal composto de dois médicos angolanos, 17 médicos expatriados (cubanos, coreanos e russos), três técnicos de nível superior, I 70 enfermeiros (as) de níveis básico e médio, bem como 122 profissionais de apoio, perfazendo um total de $3 \mid 4$ profissionais. Para a aquisição, instalação e manutenção dos equipamentos, o hospital conta com o apoio de diferentes empresas fornecedoras, das quais se destacam a Comidis (angolana), a Hosiptec (portuguesa), a Hostemed (angolana) e a Medical (brasileira), por meio das quais é desenvolvido o processo de aquisição de conhecimentos para manuseio dos equipamentos instalados no hospital.

Por seu turno, o Hospital Geral de Malanje é a principal unidade hospitalar da província de mesmo nome na região centro norte de Angola e conta com o apoio de diferentes empresas fornecedoras, entre as quais se destacam a AGEM (espanhola) e a Criavant (portuguesa) e, por intermédio delas, são desenvolvidos os processos de transferência de conhecimentos de alguns equipamentos instalados no hospital. O hospital foi constituído em 1948, quando foi designado hospital provincial. Posteriormente sofreu obras de restauração e, em 2008, foi reinaugurado e elevado à categoria de hospital geral. Para o desenvolvimento desses serviços, o hospital conta com um quadro de pessoal composto por quatro médicos angolanos, 46 médicos expatriados, II licenciados (enfermagem, radiologia, laboratório, patologia e anestesia), 223 enfermeiros (as) de níveis básico e médio, cinco técnicos de radiologia, oito técnicos de análises clínicas, bem como 129 profissionais de apoio, perfazendo um total de 426 profissionais. Percebeu-se a existência de vários equipamentos de ori- gem chinesa, no Hospital Geral de Malanje, mas também a tendência no aumento de equipamentos de origem europeia. Os equipamentos estão distribuídos em várias seções, destacando-se como principais áreas o laboratório, a imagiologia, o bloco operatório, hemoterapia e estomatologia.

\section{Análise dos dados}

De forma geral, observou-se, a partir de uma análise dos dois casos que as principais características e variáveis do processo de transferência de conhecimento interfirmas no Hospital Geral do Kwanza Norte podem, também, serem observados no Hospital Geral de Malanje. Uma explicação está relacionada não apenas com a similaridade do tipo de serviços que prestam, mas também em relação ao objeto de estudo, a missão, valores e a visão dos dois hospitais. Adicionalmente, os dois hospitais pertencem ao mesmo sistema e estão sujeitos às mesmas políticas de atuação.

Desse modo, é possível constatar algumas semelhanças e divergências entre os fatores mais relevantes para o processo de transferência de conhecimento nos dois casos (Hospital Geral do Kwanza Norte e Hospital Geral de Malanje). Percebe-se que os principais fatores que afetam a transferência de conhecimento entre as empresas fornecedoras e os hospitais estudados são: (i) qualidade de relacionamento; (ii) proximidade cultural; (iii) capacidade para transferir; (iv) capacidade de absorção e (v) motivação. A seguir, são analisadas as implicações de cada um deles para o processo.

Qualidade do relacionamento. Como se pode compreender a partir da literatu$\mathrm{ra}$, a qualidade de relacionamento entre a fonte e o receptor está intimamente relacionada com a intensidade de vínculos (o 
quanto as partes se relacionam em termos de frequência e intensidade), proximidade físico-geográfica e confiança. Os vínculos entre os fornecedores e o Hospital Geral do Kwanza Norte são fracos, casuais, e os encontros ocorrem com pouca frequência. A partir desses dados, infere-se que é baixa a qualidade de relacionamento e que é agravada pelos poucos mecanismos de socialização presentes que permitiriam uma maior aproximação entre as partes e poderiam contribuir para o êxito da transferência como reuniões, formações frequentes, equipes conjuntas. $A$ falta de programas de formação oferecidos pelos fornecedores de equipamentos dirigidos aos técnicos com vista ao manuseio adequado dos equipamentos é uma evidência negativa em relação ao que se pretende como melhoria em termos de qualidade de relacionamento entre o hospital e os fornecedores. Os poucos contatos entre as partes acontecem no momento da manutenção de um equipamento solicitado pelo hospital. A necessidade de estabelecer um protocolo entre as empresas e o hospital que inclua, não apenas a manutenção dos equipamentos, mas, também, a formação dos técnicos foi evidenciada como parte importante no relacionamento entre as partes.

Em relação ao segundo caso, percebese nos relatos que a maior parte dos indivíduos considera bom o relacionamento entre os fornecedores e hospital, pelo fato de facilitar e tornar célere o processo de aquisição, instalação e manutenção dos equipamentos, assim como o treinamento dos profissionais para a utilização dos equipamentos, mesmo com a existência de equipamentos de origem chinesa que, em determinados momentos, tem causado alguns problemas para o desempenho das atividades. Segundo relatos, esse nível de relacionamento entre o hospital e seus fornecedores tem contribuído para que os equipamentos sejam instalados e a manutenção realizada, acompanhadas de formações aos técnicos dos setores envolvidos.

Chama atenção, nesse caso, a questão da distância físico-geográfica entre as empresas fornecedoras e os hospitais, no qual existe maior dificuldade com empresas chinesas, não apenas pela distância em si, mas, também, por falta de uma representação no país (subsidiária), que facilite o contato e a troca de experiência. De modo contrário, as empresas portuguesas começaram a montar subsidiárias que tendem a facilitar o contato com o hospital, como é o caso da empresa Hospitec. Outro ponto relevante é a confiança, descrita como a capacidade das partes em acreditar que o comportamento da contraparte continuará a ser coerente no futuro e se comprometerá a cumprir com as suas obrigações. No caso do Hospital Geral do Kwanza Norte, foi relatada a necessidade do estabelecimento de contratos de prestação de serviços para se melhorar a qualidade do relacionamento com os fornecedores.

Proximidade Cultural. $O$ segundo fator, a proximidade cultural tem criado dificuldades para a transferência de conhecimento principalmente como consequência de diferenças de línguas entre grande parte dos fornecedores especialmente os chineses e dos manuais apresentados e a língua local do receptor. $O$ idioma apresentado nos manuais é, em geral, considerado como um dos principais problemas relacionados com a transferência de conhecimentos tecnológicos, bem como para a compreensão dos equipamentos instalados nos hospitais, posto que o manual é um conhecimento 
codificado, tendo sido considerado pelos entrevistados como bastante útil para o manuseio correto do equipamento. A compreensão das instruções dos equipamentos de origem europeia, como portuguesas, espanholas e italianas, tem sido mais fácil.

Pouco foi mencionado pelos entrevistados a respeito dos valores e crenças entre fornecedores e o Hospital Geral do Kwanza Norte. Contudo, aqueles que mantêm um contato mais próximo com os fornecedores alegam que os fornecedores têm valores e crenças bem diferentes em relação ao hospital. A proximidade cultural, também, é descrita nos relatos como algo que facilita não só a utilização por parte dos técnicos, mas também torna viável a sua manutenção e reparação em caso de algum problema, bem como para a compra de reagentes que permitem a calibração dos equipamentos.

Capacidade para transferir e motivação da fonte. Em relação aos fatores localizados estritamente na fonte, discutidos anteriormente, apresentam-se dois mais relevantes: capacidade de transferir e motivação para ensinar. A transferência dos conhecimentos depende em grande parte da capacidade que a detentora do conhecimento tem para passar o mesmo para o receptor. Embora, na maior parte dos relatos, aponte-se para existência de transferência de conhecimento por parte das empresas fornecedoras, é possível compreender que parte deles não tem se realizado, de maneira tal que os técnicos, ao terminarem a formação, sintam-se satisfeitos ou que recebam os conhecimentos que eles gostariam que Ihes fossem transmitidos.

A capacidade para transferir é sustentada pelos recursos humanos, técnicos e pelos os mecanismos de transferência. Nos casos estudados, os fornecedores utilizamse, na sua maioria, de mecanismos formais de transferência de conhecimentos. Em geral, os equipamentos foram apenas instalados e acompanhados de manuais dos quais muitos se apresentavam em língua estrangeira não dominada pelos técnicos. Nesse processo, foram apenas transferidos conhecimentos codificados, ainda assim, com deficiência, em alguns casos, em razão do idioma em que estavam os manuais. No caso do hospital de Kwanza Norte, a instalação de equipamentos sem um processo adequado, que idealmente incluiria a formação de pessoal, foi narrada como uma situação que frequentemente acontece tal como se depreende no seguinte relato: “(...) os aparelhos são deixados no hospital sem formação, ou melhor, nunca vem um técnico para explicar como funciona o aparelho que foi instalado" (Entrevista I).

$\mathrm{Na}$ ausência de vínculos mais estreitos, a transferência de conhecimento tem se realizado exclusivamente por meio de manuais que, embora úteis, não são capazes de auxiliar os técnicos em questões críticas ou resolução de problemas críticos de uso dos equipamentos. Nas poucas ocasiões em que os fornecedores tiveram contato com os técnicos do hospital, apenas limitavam-se a explicar como ligar e desligar o equipamento. Devido à forma rápida como alguns treinamentos são realizados, os conhecimentos tácitos mais valiosos não são compartilhados ou internalizados pelos usuários. Portanto, evidencia-se a ausência dos mecanismos de personalização que permitiriam um contato intenso entre a fonte e o receptor, bem como a transferência do conhecimento tácito mais adequada. Desse ponto de vista, pode-se inferir que a capacidade de transferir das fontes é baixa, 
considerando-se a pouca variedade de mecanismos utilizados.A motivação da fonte é também considerada um fator importante para a transferência de conhecimento, porém percebe-se que existe pouca disponibilidade dos fornecedores, para transferir os conhecimentos.

Capacidade absortiva e motivação da receptora. Concebida como a capacidade de reconhecer o valor de novos conhecimentos, bem como de assimilar e usar esse conhecimento, a capacidade absortiva é constituída, essencialmente, pela soma das capacidades de absorção de colaboradores. A capacidade de absorção de uma organização não se refere apenas à aquisição e a assimilação do conhecimento, mas, também, e, principalmente, a capacidade de transformar e explorar o referido conhecimento.

Os dados do hospital Kwanza Norte evidenciam que, durante o período de 2000 a 2013, apenas 19 atividades de formação foram realizadas. Já os dados do hospital de Malanje são um pouco melhores e indicam que, a partir do ano 2009, vem sendo incrementadas as atividades de formação. No período de 2009 a 2014, o hospital registrou 44 atividades formativas em diversas áreas. Associado ao número reduzido de quadros formados em diversas áreas, pode-se compreender que pouco se tem registrado em relação ao desenvolvimento da capacidade de absorção dos técnicos do hospital. Dados apontam, por exemplo, que os técnicos da seção de imagiologia tiveram a última formação no ano de 2000.

Os aspectos apontados acima, como a falta de formação contínua, a insuficiência de quadros qualificados, contribuem de forma negativa para o desenvolvimento da capacidade absortiva individual. A baixa capacidade absortiva é evidenciada no
Hospital Geral de Kwanza Norte no fato de que existem equipamentos que não são manuseados e outros que são manuseados com certa dificuldade por falta de conhecimento suficiente que permita a utilização dos mesmos. No caso do Hospital Geral de Malanje, a programação feita pela área de formação contínua para a realização de treinamentos tem contribuído de forma positiva para a melhoria da capacidade de absorção dos técnicos e para a melhor compreensão dos conhecimentos recebidos durante o processo de transferência.

Em relação à capacidade de absorção do Hospital Geral de Malanje, pode-se inferir que tem ocorrido melhoria, o que é evidenciado pela maior frequência de atividades de formação e o aumento no número de profissionais qualificados. Apesar de o mais adequado, é possível perceber que a dinâmica que o hospital tem implementado na área de formação tem contribuído para melhorar a capacidade de absorção dos profissionais e do hospital.

Para o desenvolvimento da capacidade de absorção, é necessário, também, que o indivíduo ou a organização receptora tenham interesse em adquirir, utilizar e absorver um determinado conhecimento, - que se designa como motivação para aprender. Apesar da fraca atividade de formação, há entre os profissionais um crescente interesse em absorver novos conhecimentos. Entretanto, somente o interesse em aprender não é suficiente se, por um lado, o conhecimento externo não estiver acessível e, por outra, a capacidade absortiva for baixa.

Percebe-se que é considerável a motivação de ambos hospitais para receber conhecimento de fontes externas, pois os indivíduos estão sempre disponíveis para 
participar de formações e ou para aprender, principalmente, quando se trata de equipamentos novos. Os relatos indicam que são os próprios técnicos que solicitam frequentemente a realização de palestras, workshops e seminários, porque as pessoas compreendem que devem aprender continuamente para progredirem em suas carreiras.

No caso do Hospital Geral do Kwanza Norte, o desenvolvimento da capacidade de absorção dos técnicos está relacionado também com baixos níveis de qualificação e de esforço de treinamento. Um tempo relativamente maior facilitaria a compreensão e utilização dos equipamentos sem grandes dificuldades (Entrevista 3), visto que relatos apontaram que as poucas formações realizadas não chegam a um dia de duração (Entrevistas 3, I0, I4). Em relação à motivação do hospital de Kwanza Norte para receber conhecimento vindo de fontes externas, percebe-se que é considerável, pois os indivíduos estão sempre disponíveis para participar em formações ou para aprender, principalmente, quando se trata de um equipamento novo (Entrevistas $3,4,7,11,14,15)$.

Já no caso do hospital de Malanje, apesar de alguns relatos mostrarem a necessidade de uma maior atenção por parte de alguns técnicos no sentido de um maior empenho para melhor absorver os conhecimentos, outros relatos apontam que a maior parte dos técnicos tem desenvolvido uma razoável capacidade de absorção, o que tem permitido a utilização com facilidade dos equipamentos, tão logo recebem a formação. Nesse hospital, em relação à motivação, os relatos mostraram que grande parte dos profissionais do hospital estão motivados para receber conhecimentos independentemente de quem vai transmitir.
A área de formação do Hospital Geral de Malanje tem programado várias atividades, com vista a despertar o interesse dos técnicos em aprender novos conhecimentos. Desse modo, é possível constatar algumas semelhanças e divergências entre os fatores mais relevantes para o processo de transferência de conhecimento nos dois casos (Hospital Geral do Kwanza Norte e Hospital Geral de Malanje), como mostra o Quadro 3.

\section{CONSIDERAÇÕES FINAIS}

Esta pesquisa procurou investigar e compreender os fatores indutores e restritivos do processo de aquisição de conhecimento externo nos hospitais do Kwanza Norte e de Malanje na República de Angola, com base no processo de transferência de conhecimento tecnológico derivado da aquisição de equipamentos fornecidos pelas empresas. Os dois casos investigados revelam que, na transferência de conhecimento para os hospitais a partir da aquisição de tecnologias externas, diversos fatores podem favorecer ou não o desempenho do processo. Um dos achados indica que a qualidade de relacionamento no Hospital Geral do Kwanza Norte é ruim, o que, de certa maneira, influencia de forma negativa o processo de transferência. Quanto ao Hospital Geral de Malanje, esse relacionamento é considerado melhor, fato que tem influenciado de forma mais positiva a transferência de conhecimento.

Entretanto, cabe ressaltar que embora tais diferenças, uma dificuldade comum é a qualidade de relacionamento com os fornecedores chineses, o que tem afetado negativamente a transferência de conhecimento. Constatou-se que a proximidade cultural é outro fator que, de alguma forma 
QUADRO 3 - Análise comparativa da transferência de conhecimento inter organizações no Hospital Geral do Kwanza Norte e no Hospital Geral de Malanje

\begin{tabular}{|c|c|c|c|c|}
\hline \multirow[b]{2}{*}{ Fatores } & \multicolumn{2}{|c|}{ Hospital Geral do Kwanza Norte } & \multicolumn{2}{|c|}{ Hospital Geral de Malanje } \\
\hline & $\begin{array}{c}\text { Fornecedores } \\
\text { europeus }\end{array}$ & $\begin{array}{c}\text { Fornecedores } \\
\text { chineses }\end{array}$ & Fornecedores europeus & $\begin{array}{l}\text { Fornecedores } \\
\text { chineses }\end{array}$ \\
\hline $\begin{array}{l}\text { Qualidade do } \\
\text { relacionamento }\end{array}$ & $\begin{array}{l}\text { - Vínculos infrequentes } \\
\text { entre as partes } \\
\text { - Distância física/ } \\
\text { geográfica minimizado } \\
\text { pela presente de } \\
\text { subsidiarias } \\
\text { - Laços razoáveis de } \\
\text { confiança }\end{array}$ & $\begin{array}{l}\text { - Vínculos fracos } \\
\text { entre as partes } \\
\text { - Distância física/ } \\
\text { geográfica presentes } \\
\text { - Fracos laços de } \\
\text { confiança }\end{array}$ & $\begin{array}{l}\text { - Vínculo entre as partes } \\
\text { razoável } \\
\text { - Distância física/ } \\
\text { geográfica minimizado } \\
\text { pela presente de } \\
\text { subsidiarias } \\
\text { - Laços forte de confiança }\end{array}$ & $\begin{array}{l}\text { - Baixo vínculo entre } \\
\text { as partes } \\
\text { - Distância física/ } \\
\text { geográfica mais } \\
\text { evidentes } \\
\text { - Fracos laços de } \\
\text { confiança }\end{array}$ \\
\hline $\begin{array}{l}\text { Proximidade } \\
\text { cultural }\end{array}$ & $\begin{array}{l}\text { - Mais similaridade } \\
\text { cultural e linguagem } \\
\text { comum }\end{array}$ & $\begin{array}{l}\text { - Distância cultural, } \\
\text { pela ausência de } \\
\text { valores, crenças, } \\
\text { práticas e linguagem } \\
\text { comuns }\end{array}$ & $\begin{array}{l}\text { - Mais similaridade cultural } \\
\text { e linguagem comum }\end{array}$ & $\begin{array}{l}\text { - Distância cultural, } \\
\text { pela ausência de } \\
\text { valores, crenças, } \\
\text { práticas e linguagem } \\
\text { comuns }\end{array}$ \\
\hline $\begin{array}{l}\text { Capacidade } \\
\text { de absorção e } \\
\text { motivação da } \\
\text { receptora }\end{array}$ & \multicolumn{2}{|c|}{$\begin{array}{l}\text { - Capacidade absortiva baixa } \\
\text { - Nível de qualificação dos profissionais baixo } \\
\text { - Conhecimentos prévios e básicos insuficientes } \\
\text { - Pouca contribuição da fonte para melhorar a } \\
\text { capacidade absortiva do hospital }\end{array}$} & \multicolumn{2}{|c|}{$\begin{array}{l}\text { - Capacidade absortiva baixa } \\
\text { - Nível de qualificação dos profissionais médio } \\
\text { - Conhecimentos prévios e básicos razoáveis } \\
\text { - Pouca contribuição da fonte para melhorar a } \\
\text { capacidade absortiva do hospital }\end{array}$} \\
\hline $\begin{array}{l}\text { Capacidade } \\
\text { de transferir e } \\
\text { motivação da } \\
\text { fonte }\end{array}$ & $\begin{array}{l}\text { - Capacidade de } \\
\text { transferir baixo } \\
\text { - } \quad \text { Linguagem de } \\
\text { manuais mais } \\
\text { adequados para } \\
\text { transferência } \\
\text { - Maior número } \\
\text { de treinamentos/ } \\
\text { formações para } \\
\text { transferir } \\
\text { - Nível de motivação } \\
\text { em ensinar razoável }\end{array}$ & $\begin{array}{l}\text { - Baixa capacidade } \\
\text { de transferir } \\
\text { conhecimentos } \\
\text { - Transferência } \\
\text { se restringe à } \\
\text { entrega de manuais } \\
\text { do usuário do } \\
\text { equipamento } \\
\text { - Manuais em língua } \\
\text { não acessíveis } \\
\text { - Baixo nível de } \\
\text { interesse em } \\
\text { transferir }\end{array}$ & $\begin{array}{l}\text { - Capacidade de transferir } \\
\text { razoável apesar de não } \\
\text { ser adequada } \\
\text { - Linguagem de } \\
\text { manuais mais } \\
\text { adequados para } \\
\text { transferência } \\
\text { - Maior número } \\
\text { de treinamentos/ } \\
\text { formações para } \\
\text { transferir } \\
\text { Nível de motivação } \\
\text { em ensinar razoável }\end{array}$ & $\begin{array}{l}\text { - Baixa capacidade } \\
\text { de transferir } \\
\text { conhecimentos } \\
\text { - Transferência se } \\
\text { restringe à entrega de } \\
\text { manuais do usuário do } \\
\text { equipamento } \\
\text { - Manuais em língua } \\
\text { não acessíveis } \\
\text { - Baixo nível de } \\
\text { interesse em transferir }\end{array}$ \\
\hline
\end{tabular}

Fonte: Elaborado pelos autores

tem influenciado a transferência de conhecimento em ambos os hospitais. Aspectos como valores, crenças e linguagem podem apontar para uma maior proximidade ou distância cultural nos dois casos.

Com relação à capacidade absortiva da receptora, foi possível observar uma baixa capacidade absortiva nos dois casos, em razão da pouca presença de pessoal qualificado e especialista em áreas estratégicas dos hospitais estudados, principalmente, para o caso Hospital Geral do Kwanza Norte. Em relação às empresas fornecedoras, há evidências de que uma baixa capacidade para transferir tem influenciado de forma negativa a transferência de conhecimento.

Quanto aos mecanismos de transferência, verificou-se que, em ambos os casos, foram utilizados, em sua maioria, mecanismos formais de transferência de conheci- 
mentos codificados. Nos dois casos, para além dos manuais, outros mecanismos de codificação utilizados com frequência são as normas, rotinas, procedimentos, relatórios e comunicações. Os mecanismos de personalização têm sido menos utilizados nos dois casos, porém, no Hospital Geral de Malanje, é maior a frequência de mecanismos de socialização como as visitas técnicas, reuniões, palestras, seminários e seções clinicam em níveis considerados ainda baixos. Os mecanismos de transferência tornam-se importantes para o processo, porque favorecem a qualidade de relacionamento entre as organizações, pelo fato de contribuir para aumentar o vínculo e a confiança entre as partes. Por sua vez, a utilização dos mecanismos de transferência propicia um clima que pode minimizar a percepção de distanciamento cultural que possa existir entre a fonte e o receptor, por meio da interação e comunicação frequente entre as partes (BRESMAN et al., 20I0; BJORKMAN et al., 2007; EASTERBY -SMITH et al., 2008).

A contribuição teórica deste estudo foi aprofundar a compreensão em relação aos fatores que exercem uma influencia significativa no êxito da transferência, bem como entender como esses fatores afetam a partilha de conhecimento. Além disso, a contribuição da pesquisa está relacionada com o avanço do entendimento das relações entre os fatores, sendo um conjunto de fatores e não um que afetam o processo de transferência. Nessa perspectiva, há evidências significativas de que a baixa cultura relacionada ao compartilhamento interno do conhecimento tem consequência negativa para a utilização eficiente do conhecimento adquirido externamente no caso do Hospital Geral do Kwanza Norte. Esse resultado converge com a literatura que aponta que a ausência de uma cultura de compartilhamento do conhecimento prévio é um aspecto que contribui de forma negativa para a compreensão do novo conhecimento (LANE; LUBATKIN, 1998). Por sua vez, há evidências nos estudos de que o aumento do nível da cultura de compartilhamento interno de conhecimento, como no caso Hospital Geral de Malanje, tem se transformado num incentivo para a criação e utilização de novos conhecimentos (LUBIT, 200I).

Do ponto de vista empírico, a compreensão do fenômeno da transferência e as variáveis que o influenciam pode contribuir com subsídios para que as empresas fornecedoras e os hospitais aprimorem o processo de transferência de conhecimento entre as partes e posterior compartilhamento interno nos hospitais, uma vez que há evidências das barreiras nesse processo. Em termos de relacionamento entre as partes, parece muito importante que as empresas fornecedoras promovam uma maior interação com os funcionários das áreas do hospital onde são instalados os equipamentos, antes, durante e depois da instalação dos mesmos, principalmente quando for o primeiro contato de parceria entre as partes. Esse contato frequente e personalizado pode minimizar a percepção de que transferir conhecimento seja difícil.

Apesar das contribuições teóricas e empíricas desta pesquisa, ela também apresenta limitações. As poucas atividades de investigação realizadas, a descrever o fenômeno de transferência de conhecimento em hospitais e mesmo na região, a dificuldade de acesso aos documentos relacionados à transferência de tecnologia e dos protocolos firmados entre os hospitais e as empresas fornecedoras, assim como a falta 
de contato como os fornecedores, podem ter, em algum grau, influenciado o nível de profundidade da investigação.

Não obstante as limitações deste estudo, os achados, implicações e conclusões deixam sugestões para futuras pesquisas. Primeiramente, aprofundar o entendimento sobre as relações causa e efeito entre os fatores dos diferentes contextos relaciona- dos com a transferência de conhecimento. Além disso, seria interessante analisar a transferência de conhecimento que ocorre entre empresas produtoras de equipamentos, os fornecedores e o hospital e, por fim, recomenda-se investigar mais profundamente a importância da transferência externa de conhecimento para o compartilhamento interno do conhecimento. 
AHMED DINE RABEH, Hammady; JIMENEZ-JIMENEZ, Daniel; MARTÍNEZ-COSTA, Micaela. Managing knowledge for a successful competence exploration. Journal of Knowledge Management, v. I7, n. 2, p. 195-207, 2013.

AUDRETSCH, D. B.; LEHMANN, E. E. \& WRIGHT, M. Technology transfer in a global economy. Journal Technology Transfer, v. 39, p. 30I-3I2, 2014.

ALCARÁ, A.; CHIARA, I.; RODRIGUES, J.; TOMÁEL, M.; PIEDADE, $V$. Fatores que influenciam o compartilhamento da informação e do conhecimento. Perspectivas em Ciências da informação, Belo Horizonte, v. 14, n. I, p. 170- 191, jan/abr. 2009.

ARGOTE, L.; INGRAM, P. Knowledge Transfer: A Basis for competitive and advantage in firms. Organizational Behavior and $\mathrm{Hu}$ man Decision Processes, v. 82, n. I, p. I50-162, 2000.

BARDIN, L. Análise de conteúdo. São Paulo: Edições Setenta, 201 I. BJORKMAN, I.; STAHL, G. K.; VAARA, E. Cultural differences and capability transfer in cross-border acquisitions: the mediating roles of capability complementarity, absorptive capacity, and social integration. Journal of International Business Studies, Helsinki, v. 38, p.658-672, 2007.

BRESMAN, Henrik; BIRKINSHAW, Julian; NOBEL, Robert. Knowledge transfer in international acquisitions. Journal of International Business Studies, v. 4I, n. I, p. 5-20, 2010.

BOZEMAN, Barry; RIMES, Heather; YOUTIE, Jan. The evolving state -of-the-art in technology transfer research: Revisiting the contingent effectiveness model. Research
Policy, v. 44, n. I, p. 34-49, 20 I 5. CAMPOS, M. Z. C. R.; FERREIRA, M. A. T.; SILVA, S. M. Disseminação e transferência do conhecimento tecnológico gerado em projetos de pesquisa e desenvolvimento no setor elétrico brasileiro. In: XXV Simpósio de gestão da inovação tecnológica. Anais ..., Brasília, out. 2008.

CASTRO, José Márcio de; GUIMARÃES, Liliane de Oliveira; DINIZ, Daniela Martins. $O$ papel dos fatores do contexto relacional na transferência de conhecimento tecnológico: um estudo de caso em uma organização pública de pesquisa agropecuária. Tourism \& Management Studies, v. 9, n. 2, p. I30-135, 2013a.

CASTRO, José Márcio de; DINIZ, Daniela; DUARTE, Roberto; DRESSLER, Marcelo; CARVALHO, Rodrigo Baroni. Fatores determinantes em processos de transferência de conhecimentos: um estudo de caso na Embrapa Milho e Sorgo e firmas licenciadas. Revista de Administração Pública, v. 47, n. 5, p. I283-I306, 20 I3b.

CHIRICO, Francesco; SALVATO, Carlo. Knowledge internalization and product development in family firms: When relational and affective factors matter. Entrepreneurship Theory and Practice, 2014. COHEN, Wesley M.; LEVINTHAL, Daniel A.; Absorptive capacity: A new perspective on learning and innovation. Administrative Science Quarterly, USA, v.35, p. 128 - 152, 1990.

DISTERER, G. Individual and social barriers to knowledge transfer. In: 34th Hawaii International Conference on System Sciences. Proceedings ..., Hawaii, 200 I.

EASTERBY-SMITH, M.; LYLES, M. A.;
TSANG, E.W. K. Interorganizational knowledge transfer: current themes and future prospects. Journal of Management Studies, v.45, n.4, p. 677-690, junho 2008.

EASTERBY-SMITH, M.; LYLES, M. A.; PETERAF, Margaret A. Dynamic capabilities: Current debates and future directions. British Journal of Management, v. 20, n. sl, p. SI-S8, 2009.

EISENHARDT, K. M. Building theories from case study research. Academy of management review, v.I4, n.4, p.532-550, 1989.

JASIMUDDIN, Sajjad M. Exploring knowledge transfer mechanisms. International Journal of Information Management, v. 27, n. 4, p. 294-300, 2007.

KUMAR, J.A.; GANESH, L.S. Research on knowledge transfer in organizations: a morphology. Journal of Knowledge Management, v. I3, n. 4, p. I6I-I74, 2009.

LAM, A. Tacit knowledge, organizational learning and societal institutions: an integrated framework. Organizations Studies, v.2I, n.3, p.487-5 I 3, 2000.

LANE, Peter J.; and LUBATKIN, Michael. Relative absorptive capacity and interorganizational learning . Strategic Management Journal, v. 19, p. 46I-477, 1998.

LI, Chia-Ying; HSIEH, Chang-Tseh.The impact of knowledge stickiness on knowledge transfer implementation, internalization, and satisfaction for multinational corporations. International Journal of Information Management, v. 29, n. 6, p. 425-435, 2009.

LIAO, S.; FEI, W.; CHEN, C. Knowledge sharing, absorptive capacity, and innovation capability: an empirical study of Taiwan's knowledge intensive industries. Journal of 
Information Science, China, v. SZULANSKI, G. Exploring internal 33, n. 3, p. 340-359, 2007.

LUBIT, R. Tacit Knowledge and Knowledge Management: the keys to sustainable competitive advantage. Organizational Dynamics, v. 29, n. 4, p.164-178, 200I.

MEYER, C. B.A case in case study methodology. Field Methods. v. I3, n. 4, p.329-352, nov. 200I.

NONAKA, I.;TAKEUCHI, H. Criação de conhecimento na empresa. Rio de Janeiro: Campus, 1997.

PÉREZ-NORDTVEDT, L.; KEDIA, B. L.; DATTA, D. K.; RASHEED, A. A. Effectiveness and efficiency of cross-border knowledge transfer: an Empirical examination. Journal of Management Studies, v. 45, n. 4, p.7I5-744, 2008. stickiness: Impediments to the transfer of best practice within the firm. Strategic Management Journal, Pennsylvania, v. 17, p. 27-43, 1996.

TSANG, Eric WK. Case studies and generalization in information systems research: A critical realist perspective. The Journal of Strategic Information Systems, v. 23, n. 2, p. I74-186, 2014.

VINDING,A.Absorptive capacity and innovative performance: a human capital approach, dez., 2000. Disponível em: http://www.druid.dk/ conferences/winter200I/paper -winter/Paper/Vinding.pdf. Acesso em: agosto, $20 \mathrm{I} 4$.

WIJK, R.; JANSEN, J. J. P.; LYLES, M. A.
Inter- and Intra-Organizational Knowledge Transfer: A Meta-Analytic Review and Assessment of its Antecedents and Consequences. Journal of Management Studies, v. 45, n. 4, p. 830-853, 2008.

YIN, Robert K. Estudo de caso: planejamento e métodos. Porto Alegre: Bookman, 2005.

ZAHRA, S.A.; GEORGE, G. Absorptive capacity: a review, reconceptualization and extension. Academy of Management Review, v. 27, p. 185-203, 2002.

ZANDER, U.; KOGUT, B. Knowledge and the speed of the transfer and imitation of organizational capabilities: an empirical test. Organization Science, v. 6, n. I, p.7692, 1995. 